\title{
Acute major pulmonary embolism as a cause of exaggerated respiratory blood pressure variation and pulsus paradoxus
}

\author{
I. G. McDonald, J. Hirsh, V. M. Jelinek, and G. S. Hale \\ From the Cardiovascular Unit and Department of Medicine, University of Melbourne, \\ St. Vincent's Hospital, Melbourne, Australia
}

Respiratory variations in systemic blood pressure were analysed in 15 patients with major pulmonary embolism. Exaggeration of systolic blood pressure fluctuation was common and occasionally severe enough to produce obvious pulsus paradoxus. The cause was usually increased pulse pressure variation, presumably attributable to corresponding changes in left ventricular stroke volume. Of possible causes considered, the most likely were left ventricular compression due to acute right ventricular dilatation or depletion of pulmonary venous volume augmenting inspiratory pooling of blood.

Pulsus paradoxus is regarded as one of the classical signs of acute cardiac tamponade but its occasional occurrence in major pulmonary

- embolism is not so well recognized. This phenomenon is important clinically, since pulmonary embolism may be mistaken for acute cardiac tamponade (Burdine and Wallace, 1965), and also theoretically, in understanding the pathological physiology of pulmonary embolism. We have studied the effects of pulmonary embolism on respiratory fluctuations in blood pressure and a group of - patients with severe embolism which had been proven angiographically (McDonald et al., 1972).

\section{Methods}

Patients studied (Table) Of 23 consecutive patients with angiographically proven acute major

- pulmonary embolism, the 15 patients selected for the present study represented all in whom the systemic arterial blood pressure had been measured during the initial cardiac catheterization. There were 8 men and 7 women with an average age of 52.7 years (range 28 to 73 years). In 8 of them there had been clinical evidence of pulmonary embolism during the 2 months preceding

- the major episode. One patient had myocardial ischaemia with pulmonary congestion but none

of the remainder had serious underlying cardiac or pulmonary disease.

Investigation Right heart catheterization was performed using an angiographic catheter (7 or

Received 20 March 1972.
8F Eppendorf, USCI) and arterial catheterization either by percutaneous catheterization of the brachial artery or by arteriotomy and cannulation of the radial artery. Intravascular pressures were measured by mutual inductance gauges (Sanborn 276b) with reference to a point $5 \mathrm{~cm}$ posterior to the sternal angle. Cardiac output was measured by the indicator dilution technique. Movements of the lower chest were monitored with a variable resistance gauge which was connected as one arm of the Wheatstone bridge circuit of the DC amplifier (Sanborn 350-3200). These physiological variables were recorded on a multichannel photographic recorder (Sanborn 564 series). The selective pulmonary angiograms

TABLE Respiratory variation in systemic arterial blood pressure

\begin{tabular}{|c|c|c|c|}
\hline & $\begin{array}{l}\triangle S B P \\
(m m H g)\end{array}$ & $\begin{array}{l}\Delta P P \\
(m m H g)\end{array}$ & $\begin{array}{l}\triangle P P / P P e x \\
(\%)\end{array}$ \\
\hline Control group & $7 \cdot 1 \pm 3 \cdot 3$ & $3 \cdot 9 \pm I \cdot 3$ & $7 \cdot 7 \pm 3 \cdot 0$ \\
\hline $\begin{array}{l}\text { Pulmonary embolis } \\
\text { (initial study) } \\
\text { Significance }\end{array}$ & $\begin{array}{l}\mathrm{II} \cdot 3 \pm 5 \cdot \mathrm{I} \\
\mathrm{P}<0.05\end{array}$ & $\begin{array}{l}8.6 \pm 4.6 \\
P<0.01\end{array}$ & $\begin{array}{l}19.8 \pm 14.5 \\
P<0.01\end{array}$ \\
\hline $\begin{array}{l}\text { Pulmonary embolis } \\
\text { Initial study } \\
\text { Early follow-up } \\
\text { Significance }\end{array}$ & $\begin{array}{l}\mathrm{II} \cdot 0 \pm 3 \cdot 8 \\
7 \cdot 3 \pm 4 \cdot 1 \\
\mathrm{P}<0.01\end{array}$ & $\begin{array}{l}7 \cdot 8 \pm 2 \cdot 6 \\
5 \cdot 2 \pm 3 \cdot 4 \\
P<0.02\end{array}$ & $\begin{array}{l}18.5 \pm 8.9 \\
9.7 \pm 5.0 \\
P<0.05\end{array}$ \\
\hline $\begin{array}{l}\text { Pulmonary embolis } \\
\text { Initial study } \\
\text { Late follow-up } \\
\text { Significance }\end{array}$ & $\begin{array}{r}\mathrm{II} \cdot 4 \pm 5.7 \\
3.8 \pm 1 \cdot 7 \\
\mathrm{P}<0.01\end{array}$ & $\begin{array}{l}9 \cdot 2 \pm 6 \cdot 0 \\
2 \cdot 3 \pm 1 \cdot 4 \\
P<0.01\end{array}$ & $\begin{array}{l}21.4 \pm 17.9 \\
4.4 \pm 3.7 \\
P<0.02\end{array}$ \\
\hline
\end{tabular}

See text for explanation of symbols. 
were recorded with a rapid film changer (ElemaSchonander). The degree of pulmonary vascular obstruction was independently estimated from this angiogram by 3 observers and the average of their estimates was recorded. Pulmonary vascular obstruction was expressed as a 'pulmonary vascular obstruction index' - the ratio of the mean pulmonary arterial pressure to the cardiac index. All haemodynamic measurements were made before the pulmonary angiogram had been performed.

The respiratory fuctuations in systemic arterial blood pressure were expressed in three ways (i) variation in systolic blood pressure $(\Delta S B P)$, (ii) variation in pulse pressure $(\Delta \mathrm{PP})$ and (iii) inspiratory reduction in pulse pressure expressed as a proportion of the maximum pulse pressure during expiration ( $\triangle \mathrm{PP} / \mathrm{PP}$ ex).

The time interval between the most recent episode of major pulmonary embolism and this study was less than 2 hours in 5 patients, between 2 and 12 hours in 5, between 12 and 48 hours in 2, and more than 48 hours in I patient. The time of pulmonary embolism could not be accurately determined in 2 patients in whom the onset of symptoms was progressive. Haemodynamic measurements and pulmonary angiography were subsequently repeated in 13 patients. The repeated study was classified as 'early' if performed I to 4 days later and 'late' if performed I week to I month after the initial study. An early restudy was performed in 8 patients. A late study was performed in 4 of these patients and in 5 others. The methods of observation and treatment of these patients during this investigation have been previously discussed in detail (McDonald et al., 1972).

Control data The effects of respiration on systemic and pulmonary arterial pressures were analysed in the routine cardiac catheterization records of 14 consecutive patients who had been studied because of suspected valvular heart disease, cardiomyopathy, pulmonary embolism, or atrial myxoma and in whom no heart or pulmonary vascular disease had been subsequently shown. Sedation of these patients was not heavy (pentobarbitane $100 \mathrm{mg}$ orally, promethazine 25-50 $\mathrm{mg}$ intramuscularly) and the respiratory rate was normal in all of them. The group comprised 8 men and 6 women with an average age of $4 \mathrm{I} \cdot 0$ years (range 21 to 64 years). Differences between haemodynamic measurements obtained in control subjects and in those with pulmonary embolism were tested for significance by the unpaired t-test, and between values for patients with pulmonary embolism between initial and follow-up studies by the paired t-test (Snedecor, 1956).

\section{Results}

At the initial study, the pulmonary artery pressure was $\overline{27.3} \pm 6.2 \mathrm{mmHg}$, the cardiac index $\overline{2.53} \pm 0.83 \mathrm{l} . / \mathrm{min} / \mathrm{m}^{2}$, the vascular obstruction index $\overline{12 \cdot 3} \pm 6.05 \mathrm{mmHg} / 1 . / \mathrm{min} / \mathrm{m}^{2}$, pulmonary vascular obstruction (angiographic) $\overline{57.3} \pm 13.6$ per cent, heart rate $\overline{\text { II } 5 \cdot 6} \pm$ II. 3 beats $/ \mathrm{min}$, and systemic arterial pressure $\overline{88 \cdot 4} \pm 17 \cdot 3 \mathrm{mmHg}$.

The effects of respiration on the systemic arterial blood pressure have been compared for the control group and patients with major pulmonary embolism (Table). The respiratory fluctuations in systemic arterial blood pressure were abnormally large at the initial study in patients with major pulmonary embolism but later returned to normal. Thus, the mean values of $\triangle S B P, \triangle P P$, and $\triangle P P /$ PPex were all significantly increased above the control values at the initial study but a conspicuous reduction had occurred by the time of the late studies when only one of the

FIG. I (a) Conspicuous pulsus paradoxus shown in recording of systemic arterial blood pressure of Case 13, initial study. Upward deflection of respiration record indicates inspiration. Heavy time lines recorded each second. (b) Similar recordings at the follow-up study one month later. The pulsus paradoxus was no longer present.
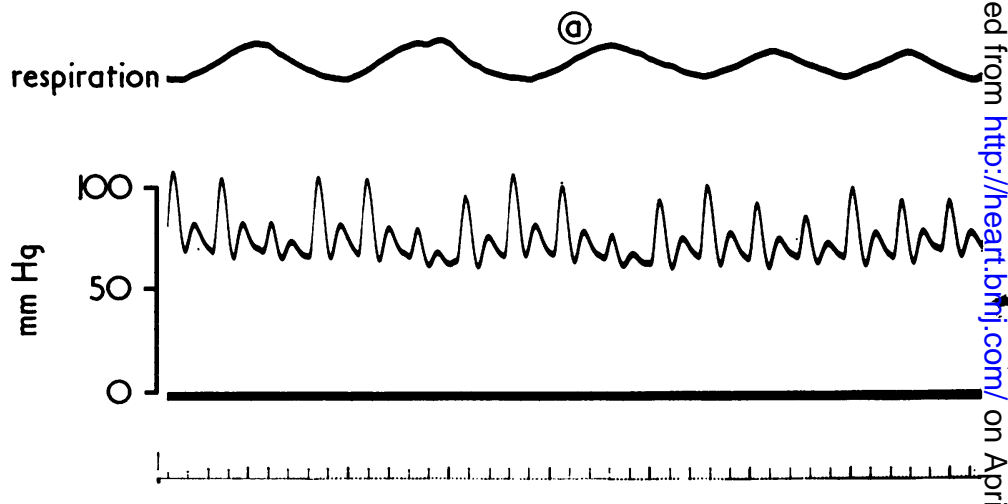

(b)
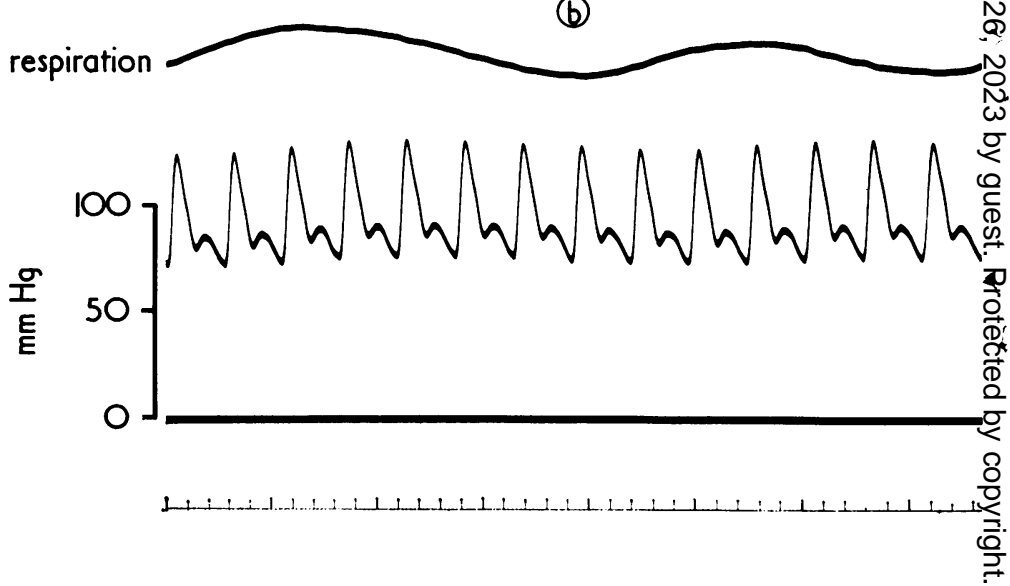
measurements was significantly different from the control values. An example of severe respiratory reduction of pulse pressure, obvious clinically as pulsus paradoxus, and its subsequent return to normal is shown in Fig. I.

The normal range of respiratory variation in systolic blood pressure $(\triangle S B P)$ was wide, and abnormal values (mean value $+2 S D$ ) were recorded in only 4 of the 15 patients. However, pulse pressure fluctuations $(\Delta P P)$ were abnormal in 9 patients and the proportionate inspiratory reduction in pulse pressure $(\Delta \mathrm{PP} / \mathrm{PPex})$ was abnormal in 9 patients. One of these measurements was abnormal in II of the 15 patients. It is noteworthy that the $\Delta \mathrm{PP} / \mathrm{PPex}$ was abnormal in 5 of the 6 patients studied within 2 hours of major pulmonary embolism but in only 4 of the remaining 9 patients seen later. The mean value of the vascular obstruction index was 14.7 in patients with an abnormal $\triangle \mathrm{PP} / \mathrm{PPex}$ and 8.8 in those with a normal value.

Pulsus paradoxus was obvious during routine arterial palpation in 3 patients, in all of whom the abnormal fluctuation was almost entirely attributable to pulse pressure changes with little change in diastolic blood pressure. The patient who had pulmonary venous congestion in addition to severe pulmonary embolism had a large respiratory variation in systolic blood pressure caused by fluctuations in both pulse pressure and diastolic blood pressure, but pulsus paradoxus was not noted clinically in this patient.

\section{Discussion}

Quantitation of pulsus paradoxus The term 'pulsus paradoxus' was coined to describe the detection by arterial palpation of an abnormally large inspiratory reduction in amplitude of the arterial pulse (Shapiro and Salick, 1965; Gauchat and Katz, 1924). The conventional method of measuring this phenomenon has been to quote the peak difference between the inspiratory and expiratory systolic blood pressures. However, the use of systolic blood pressure fluctuations $(\triangle \mathrm{SBP})$ as the sole index of severity of pulsus paradoxus is unsatisfactory, since there is need to distinguish 2 important factors that - contribute to respiratory variation in systolic blood pressure (Fig. 2): (I) fluctuations in left ventricular stroke volume producing corresponding changes in the systemic arterial pulse pressure $(\Delta P P)$, and $(2)$ variation in intrapleural pressure during the respiratory cycle which is passively transmitted to the heart and intrathoracic blood vessels to cause

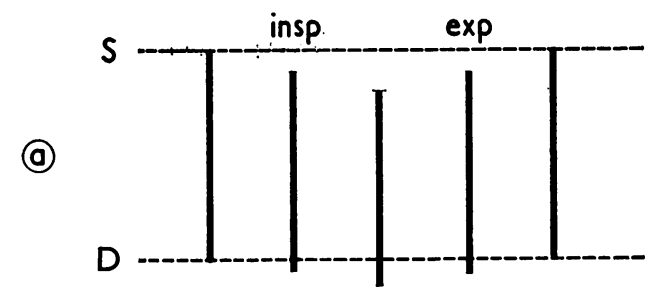

(b)

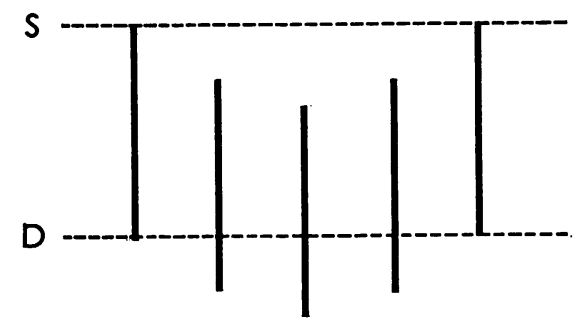

(c)

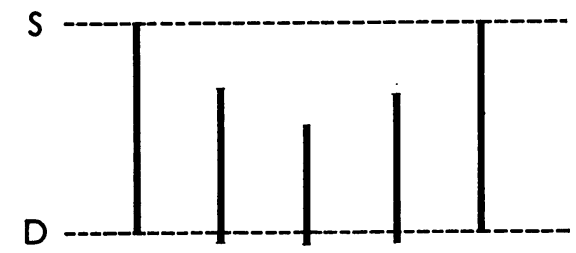

FIG. 2 Diagrammatic representation of respiratory fluctuations in systolic blood pressure: (a) due to small variations in diastolic blood pressure and pulse pressure in a normal subject, $(b)$ due to variation in diastolic blood pressure but not pulse pressure with increased fluctuation in intrapleural pressure, and (c) due mainly to large variations in pulse pressure in cardiac tamponade or pulmonary embolism. INSP = inspiration; $E X P=$ expiration.

fluctuation in both systolic and diastolic blood pressures (Lauson, Bloomfield, and Cournand, 1946; Dornhorst, Howard, and Leathart, I952; Shabetai, Fowler, and Gueron, 1963). Using the index $\Delta P P / P P e x$ as a measure of pulsus paradoxus has two advantages. First, it has a sound physiological basis, since its value should be proportional to corresponding respiratory changes in left ventricular stroke volume (see Appendix). In fact, it has been shown experimentally that the pulse pressure and stroke volume correlate closely with one another in an individual subject over short time intervals (Osborn et al., 1968). The second advantage of this index is that it reflects proportional changes in pulse pressure with respiration and it has been shown that a smaller variation in pulse pressure can be detected clinically when the blood 
pressure is low and the pulse pressure small (Spodick, 1967).

Respiration and blood pressure in normal subjects The average inspiratory reduction in arterial systolic blood pressure is small in normal people and includes a component due to passive transmission of changes in intrapleural pressure affecting the diastolic blood pressure as well as fluctuations in pulse pressure presumably due to variations in left ventricular stroke volume. The cause of the inspiratory reduction in left ventricular stroke volume in normal people is still in dispute. There is some evidence to suggest that it represents a much larger respiratory fluctuation in right ventricular stroke volume which has been damped and delayed in the pulmonary circulation (Shabetai et al., 1963; Dornhorst et al., 1952; Franklin, Van Citters, and Rushmer, 1962; Hoffman et al., 1965; Goldblatt et al., 1963; Guntheroth, Morgan, and Mullins, 1967), but it has also been suggested that inspiration might have a more direct effect in reducing left ventricular volume and stroke volume in normal subjects (Shabetai et al., 1963; Dornhorst et al., 1952).

Respiration and blood pressure in pulmonary embolism Though it is possible that other factors such as obesity (Lange, Botticelli, and Tsagaris, 1964) or shock (Cohn, Pinkerson, and Tristani, 1967) could have contributed to increased respiratory variation in blood pressure in our patients, it is clear that major pulmonary embolism was the main cause. Furthermore, it was shown that the respiratory variations in systolic blood pressure were mainly attributable to pulse pressure changes and hence presumably to changes in left ventricular stroke volume. Not surprisingly, the evidence suggested that these changes were more conspicuous soon after embolism and in those with more severe pulmonary vascular obstruction.

The cause of pulsus paradoxus in major pulmonary embolism has not been studied experimentally. Hence, possible mechanism can only be sought by analogy from studies in acute cardiac tamponade. Respiratory fluctuations in right ventricular stroke volume have been found to be unchanged in dogs with experimental acute cardiac tamponade, but, since the stroke volume was reduced, these fluctuations were relatively greater. The exaggerated respiratory variations in stroke volume were then thought to be passively trarsmitted by the pulmonary circulation to the left ventricle to cause pulsus paradoxus (Gunteroth et al., 1967). However, other workers have postulated that inspiration directly impedes left ventricular filling and hence reduces the left ventricular stroke volume either by increasing the inspiratory capacity of the pulmonary veins during inspiration causing excessive 'pooling' of blood (Sharp et al., 1960; Golinko, Kaplan, and Rudolph, 1963) by stretching the pericardium (Dock, I961) or by compression of the left ventricle due to the normal inspiratory increase in right ventricular volume (Dornhorst et al., 1952; Shabetai et al., I965; Gabe et al., 1970). The last mechanism could be postulated to explain exaggeration of respiratory fluctuations of left ventricular stroke volume in major pulmonary embolism. Thus, acute right ventricular distension after pulmonary embolism could cause left ventricular compression which would be aggravated by the increased right ventricular volume accompanying inspiration. Alternatively, acute pulmonary arterial obstruction could reduce the pulmonary venous volume, permitting greater 'pooling' of blood during inspiration. Finally, as in experimental cardiac tamponade, respiratory variations in right ventricular stroke volume might be unchanged but large relative to the low stroke volume after major pulmonary embolism. Passive transmission of this fluctuation to the left heart could similarly cause pulsus paradoxus. It seems that these possibilities will be best explored by controlled animal experiments.

\section{References}

Burdine, J. A., and Wallace, J. M. (1965). Pulsus paradoxus and Kussmaul's sign in massive pulmonary embolism. American fournal of Cardiology, 15, 413.

Cohn, J. N., Pinkerson, A. L., and Tristani, F. E. (1967). Mechanism of pulsus paradoxus in clinical shock. Fournal of Clinical Investigation, 46, 1744.

Dock, W. (196I). Inspiratory traction on the pericardium: the cause of pulsus paradoxus in pericardial disease. Archives of Internal Medicine, 108, 837.

Dornhorst, A. C., Howard, P., and Leathart, G. L. (1952). Pulsus paradoxus. Lancet, I, 746.

Franklin, D. L., Van Citters, R. L., and Rushmer, R. F. (1962). Balance between right and left ventricular output. Circulation Research, I0, 17.

Gabe, I. T., Mason, D. T., Gault, J. H., Ross, J., Zelis, R., Mills, C. J., Braunwald, E., and Shillingford, J. P. (1970). Effect of respiration on venous return and stroke volume in cardiac tamponade. British Heart Fournal, 32, 592.

Gauchat, H. W., and Katz, L. N. (1924). Observations on pulsus paradoxus (with special reference to pericardial effusions). I Clinical. Archives of Internal Medicine, 33, 350. 
Goldblatt, A., Harrison, D. C., Glick, G., and Braunwald, E. (1963). Studies on cardiac dimensions in intact unanesthetized man II. Effects of respiration. Circulation Research, 13, 455.

Golinko, R. J., Kaplan, N., and Rudolph, A. M. (1963). The mechanism of pulsus paradoxus during acute pericardial tamponade. Fournal of Clinical Investigation, 42, 249.

Guntheroth, W. G., Morgan, B. C., and Mullins, G. L. (1967). Effect of respiration on venous return and stroke volume in cardiac tamponade. Mechanism of pulsus paradoxus. Circulation Research, 20, 381.

Hoffman, J. I. E., Guz, A., Charlier, A. A., and Wilcken, D. E. L. (1965). Stroke volume in conscious dogs; effect of respiration, posture, and vascular occlusion. Fournal of Applied Physiology, 20, 865 .

Lange, R. L., Botticelli, J. T., and Tsagaris, T. T. (I964). Spurious signs of cardio-respiratory disease in obesity and ascites. Obligatory venous hypertension and respiratory arterial pressure variation (Abstract). Fournal of Clinical Investigation, 43, 1235.

Lauson, H. D., Bloomfield, R. A., and Cournand, A. (1946). The influence of respiration on the circulation in man. American fournal of Medicine, 1, 315.

McDonald, I. G., Hirsh, J., Hale, G. S., and O'Sullivan, E. F. (1972). Major pulmonary embolism, a correlation of clinical findings, haemodynamics, pulmonary angiography and pathological physiology. British Heart fournal, 34, 356.

Osborn, J. J., Russell, J. A. G., Beaumont, J., deLanerolle, P., McChesney, B., and Garfield, F. (1968). The measurement of relative stroke volume from aortic pulse contour of pulse pressure. Vascular Diseases, 5, 165.

Shabetai, R., Fowler, N. O., Fenton, J. C., and Masangkay, M. (1965). Pulsus paradoxus. fournal of Clinical Investigation, 44, 1882.

Shabetai, R., Fowler, N. O., and Gueron, M. (1963). The effects of respiration on aortic pressure and flow. American Heart Fournal, 65, 525.

Shapiro, E., and Salick, A. I. (1965). A clarification of the paradoxic pulse. Adolf Kussmaul's original description. American fournal of Cardiology, 16, 426.

Sharp, J. T., Bunnell, I. L., Holland, J. F., Griffith, G. T., and Greene, D. G. (1960). Haemodynamics during induced cardiac tamponade in man. American fournal of Medicine, 29, 640.
Snedecor, G. W. (1956). Statistical Methods, 5th ed., p. 35. Iowa State College Press, Ames, Iowa.

Spodick, D. H. (1967). Acute cardiac tamponade. Pathologic physiology, diagnosis and management. Progress in Cardiovascular Diseases, 10, 64.

Requests for reprints to Dr. Ian G. McDonald, Cardiovascular Unit, St. Vincent's Hospital, Victoria Parade, Fitzroy 3065, Melbourne, Australia.

\section{Appendix}

Relation of proportionate change in systemic arterial pulse pressure during the respiratory cycle to the proportionate change in left ventricular stroke volume.

Let $\mathbf{P P}_{1 \mathrm{in}}, \mathrm{PP}_{\mathrm{ex}}$ represent the minimum inspiratory and maximum expiratory left ventricular pulse pressures.

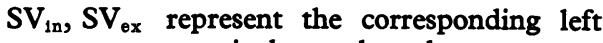
ventricular stroke volumes.

C represents the average arterial compliance (SV/PP) over the range of arterial pressures measured.

$\triangle \mathrm{PP} \quad$ represents the respiratory pulse pressure variation $\left(\mathrm{PP}_{\mathrm{ex}}-\mathrm{PP}_{\mathrm{in}}\right)$.

$\Delta S V \quad$ represents the respiratory stroke volume variation $\left(\mathrm{SV}_{\mathrm{ex}}-\mathrm{SV}_{\mathrm{in}}\right)$.

Then

That is

$$
\begin{aligned}
& S V_{1 n}=C \cdot P_{1 n} \\
& \mathrm{SV}_{\mathrm{ex}}=\mathrm{C} \cdot \mathrm{PP}_{\mathrm{ex}} \\
& \frac{S V_{e x}-S V_{i n}}{S V_{e x}}=\frac{C \cdot P P_{e x}-C \cdot P P_{1 n}}{C \cdot P P_{e x}} \\
& =\frac{\mathbf{P P}_{\text {ex }}-\mathbf{P P}_{\mathrm{tn}}}{\mathbf{P P}_{\mathrm{ex}}}
\end{aligned}
$$

$\frac{\Delta \mathrm{SV}}{\mathrm{SV}_{\mathrm{ex}}}=\frac{\Delta \mathrm{PP}}{\mathrm{PP}_{\mathrm{ex}}}$ 